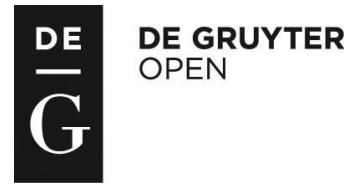

\title{
ESTIMATION OF MEAT CONTENT IN THE CARCASSES OF YOUNG PIGS BASED ON PERFORMANCE TESTING OF LIVE ANIMALS AND CARCASS EVALUATION*
}

\author{
Magdalena Szyndler-Nędza ${ }^{1 \bullet}$, Robert Eckert ${ }^{1}$, Tadeusz Blicharski ${ }^{2}$ \\ ${ }^{1}$ Department of Genetics and Animal Breeding, National Research Institute of Animal Production, \\ 32-083 Balice n. Kraków, Poland \\ ${ }^{2}$ Institute of Genetics and Animal Breeding, Polish Academy of Sciences, Postępu 36A, \\ Jastrzębiec, 05-552 Magdalenka, Poland \\ •Corresponding author: magdalena.szyndler@izoo.krakow.pl
}

\begin{abstract}
The aim of the study was to develop new equations for the estimation of meat percentage in the carcasses of young pigs, based on examination of the current pig population. In addition, new regression equations were constructed to predict the weight of meat in primal cuts. In both cases, the estimates were based on performance testing of live animals and post-slaughter evaluation of carcass traits in these animals. The study was conducted on 654 gilts of six breeds. Performance testing of live animals and carcass evaluation were performed at the Pig Testing Station (SKURTCh). Performance records in live animals included body weight (BW [kg]), age (A [days]), daily weight gain (DG [g/day]), and ultrasonic measurements, using a Piglog 105 ultrasound apparatus: backfat thickness at P2 and P4 and loin eye height P4M (at P4). Then the gilts were slaughtered and, after being chilled for 24 hours at $4^{\circ} \mathrm{C}$, the right half-carcass was dissected into primal cuts. These cuts were then subjected to detailed dissection, which provided the basis for determination of the weight of meat in the primal cuts $\mathrm{E} 2[\mathrm{~kg}]$ and meat percentage in the carcass $\mathrm{E} 1$ [\%]. An array of linear models based on multiple regression was constructed to estimate meat percentage in the carcass $[\%]$ and weight of meat in primal cuts $[\mathrm{kg}]$. It was found that the developed linear regression equations for all breeds, which estimated meat content in the carcass based on three variables (classical model: P2, P4 and P4M), were characterised by the following values of standard error of the estimate RSE and correlation coefficient $\mathrm{R}$ : for $\mathrm{E} 1[\%], \mathrm{RSE}=3.33 ; \mathrm{R}=0.63$; for $\mathrm{E} 2[\mathrm{~kg}], \mathrm{RSE}=1.65 ; \mathrm{R}=\mathbf{0 . 5 8}$. The addition to the classical model of a variable describing the breed greatly improved the parameters of the equation predictive of $\mathrm{E} 1(\mathrm{RSE}=3.02 ; \mathrm{R}=0.71)$. The model predictive of $\mathrm{E} 2$ was obtained by the addition of two variables: breed and carcass weight on the day of measurement $(\mathrm{RSE}=1.37 ; \mathrm{R}=\mathbf{0 . 7 3})$. In general, the present studies indicate that equations estimating the weight of meat in a carcass $(\mathrm{E} 2[\mathrm{~kg}])$ based on performance testing of live animals are characterised by a much lower value of standard error (RSE) than equations estimating meat percentage in the carcass of the same pigs $(\mathrm{E} 1[\%])$, including those currently used in practice.
\end{abstract}

Key words: pigs, performance testing in live animals, carcass evaluation, meat percentage in carcasses, weight of meat in cuts, regression equations

\footnotetext{
*The work was funded by the National Science Centre, project no. N N311 082240.
} 
It is assumed that, apart from BLUP and genomic evaluation, testing of the performance of animals is the basic criterion for selection in breeding programmes aimed at improving pig breeds. Determination of daily gains and meat content are important components of performance testing, estimated using regression equations based on ultrasonic measurements of backfat thickness and height of the longissimus dorsi. The linear regression equation currently used in performance testing was developed based on a breeding boar population in 2004 (Szyndler-Nędza and Różycki, 2005). Obviously, over the course of time, selection causes changes in the mean values of performance parameters in a given population, including meat content in the carcass. Improvement of this parameter is associated with an increase in the weight of meat in primal cuts and a decrease in fat content in the carcass (Szyndler-Nędza and Mucha, 2006). In addition, selection changes the proportion between intramuscular fat in cuts and total fat (Kouba et al., 1999). These changes, which result from genetic changes in the rate of muscular tissue growth (Schwab et al., 2007), increase the error in the equation estimating the meatiness of young animals. According to the authors, they were the result of intensive selection for a group of highly mutually correlated, economically important traits. Correlation coefficients between traits used for establishing the breeding value of animals change over years of selection. Studies by Szyndler-Nędza et al. (2012) conducted on Polish Large White (PLW) and Polish Landrace (PL) boars selected for meatiness demonstrated a statistically important decrease in correlation coefficients between backfat thickness measurements or loin eye height and meat content in the carcass. These authors and others, such as Zelenák et al. (2005), Nissen et al. (2006), Engel et al. (2012), and Lisiak and Borzuta (2014), based on investigations of the pig population, demonstrated the need for the adjustment of regression equations, which change with the changing slaughter value of fatteners, for different genetic types of pigs. Periodical verification of these equations was recommended.

Considering the observed changes in meat percentage in carcasses and the related shift in the weight of meat in primal cuts, the aim of the present study was to develop new equations for estimation of meat percentage in the carcasses of young pigs and the weight of meat in primal cuts for the current pig population based on performance testing of live animals and evaluation of carcass traits.

\section{Material and methods}

The study was conducted on 654 gilts of six breeds (161 Polish Large White (PLW), 251 Polish Landrace (PL), 29 Puławska, 12 Hampshire, 99 Duroc, 102 Pietrain pigs) performance-tested at the Pig Testing Station (SKURTCh). Gilts were fattened to $100 \mathrm{~kg}$ and performance-tested at this body weight. The following parameters were recorded: body weight (BW $[\mathrm{kg}]$ ), age (A [days]), daily gain (DG [g/day]), and ultrasonic measurements with a Piglog 105 ultrasound apparatus: backfat thickness at: P2 (mm) (behind the last rib, 3 off the midline), P4 (mm) (behind the last rib, $8 \mathrm{~cm}$ off the midline) and loin eye height $\mathrm{P} 4 \mathrm{M}(\mathrm{mm})$ at $\mathrm{P} 4$. Then the gilts 
were slaughtered and subjected to dissection according to the procedure used at the Pig Testing Station (Różycki and Tyra, 2010). Carcasses were chilled at $4^{\circ} \mathrm{C}$ for $24 \mathrm{~h}$, and the right half-carcass was dissected into primal cuts (ham, shoulder, neck, loin, tenderloin, belly, ribs, shank). These cuts were dissected further to isolate muscular tissue, fat and bones. The detailed dissection was the basis for determination of the weight of meat in primal cuts E2 [kg] according to the formula:

$$
E 2=m a+m b+m c+m d+m e+m f+m g+m h
$$

where:

$m a$ - weight of meat in the ham,

$m b$ - weight of meat in the shoulder,

$m c$ - weight of meat in the neck,

$m d$ - weight of meat in the loin,

$m e$ - weight of meat in the tenderloin,

$m f$ - weight of meat in the belly,

$m g$ - weight of meat in the ribs,

$m h$ - weight of meat in the shank;

and meat percentage in the carcass E1 (\%) according to the formula:

$$
E 1=E 2 * 100 /(M a+M b+M c+M d+M e+M f+M g+M h)
$$

where:

E2 - weight of meat in primal cuts,

$M a$ - ham cut weight,

$M b$ - shoulder cut weight,

$M c$ - neck cut weight,

$M d$ - loin cut weight,

$M e$ - tenderloin cut weight,

$M f$ - belly cut weight,

$M g$ - rib cut weight,

$M h$ - shank cut weight.

Carcasses were characterised based on the means and standard deviations calculated for each breed and for all breeds combined. For the obtained data, Pearson correlations between variables were estimated. Due to the limited data for some breeds, data were divided into three breed groups: maternal breeds (PLW, PL), native breed (Puławska), paternal breeds (Hampshire, Duroc, Pietrain). The Puławska breed was not included in maternal breeds due to significantly different backfat thickness and meatiness in comparison with PLW and PL. Then, in order to estimate meat percent- 
age in the carcass $(\%)$ and weight of meat in primal cuts $(\mathrm{kg})$, an array of linear models were constructed based on multiple regression. The linear models were created for each breed group separately and for all breeds combined, based on a combination of independent variables:

- a classical model using the full complement of basic data from performance testing of live animals (P2, P4, P4M),

- models including additional variables: body weight on the day of measurement (BW), daily gain (DG), age on the day of measurement (A) and breed (Breed).

The variable 'Breed' was used only in models constructed for all breeds combined. This variable was coded by a zero-one matrix (the first breed (PLW) was a reference point for the remaining breeds). Linear regression equations were estimated according to the following model:

$$
y=\alpha_{0}+\alpha_{t} x_{1}+\ldots+\alpha_{k} x_{k}+\varepsilon
$$

where:

$y$ - dependent variable E1 or E2 (to be predicted),

$x_{1}, x_{2}, \ldots x_{k}$-independent variables (used to predict),

$\alpha_{0}, \alpha_{1}, \ldots, \alpha_{k}$ - parameters of regression function (parameters of the model),

$\varepsilon-$ the regression residual.

Then, based on the Residual Standard Error (RSE) of the estimate and multiple correlation coefficient (R), the best fit was selected from among the developed models. The calculations were conducted using the statistical software programs Matlab and Statistica.

\section{Results}

The study evaluated a total of 654 gilts of six breeds. Analysis of the mean values for individual breeds (Table 1) showed that maternal breeds (PLW and PL) were characterised by similar daily gains and age on the day of slaughter. These breeds differed in backfat thickness and meat content. Among gilts of paternal breeds, Hampshire pigs were distinguished by the largest daily gains and the shortest fattening period; moreover, these pigs were characterised by the thickest mean back and flank fat and the lowest meat content as determined by detailed dissection. Compared to the remaining breeds, the native breed Puławska was characterised by the smallest daily gains and thickest flank fat (P4), and by meat content in the carcass obtained after dissection comparable to Hampshire and Duroc pigs. 


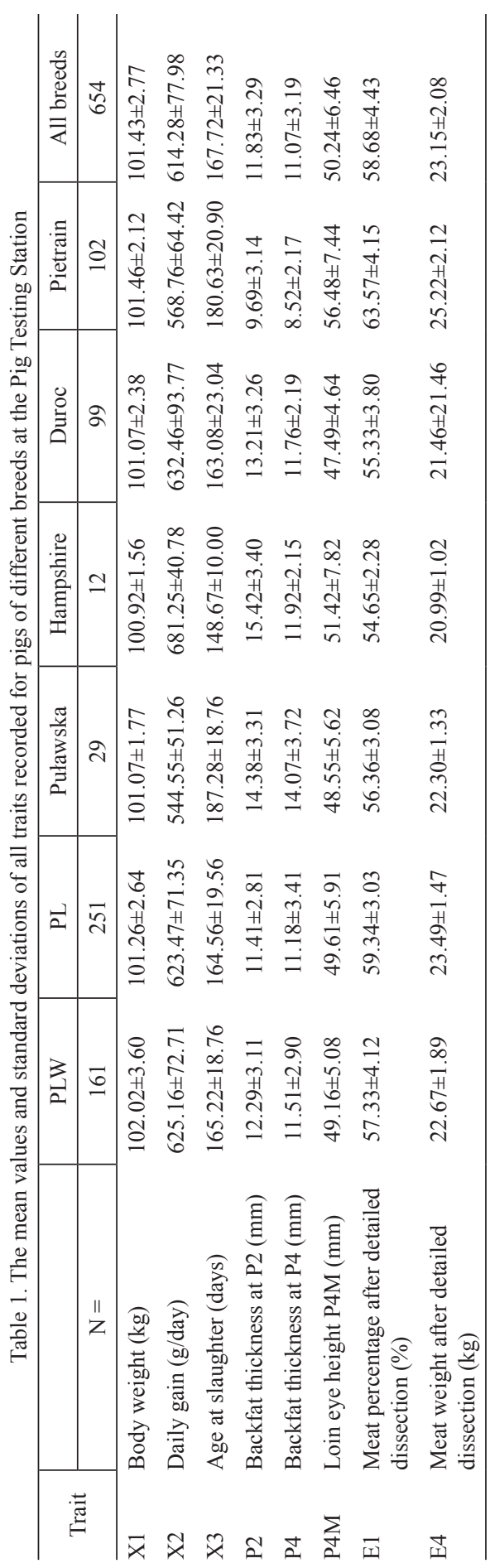


Table 2 presents Pearson correlation coefficients between input basic data and output variables (estimated). The correlations were estimated within three breed groups: maternal, Puławska, and paternal breeds. In all breed groups, input variables P2 and P4 were highly statistically significantly correlated $(\mathrm{P} \leq 0.01)$ with each other. A highly statistically significant $(\mathrm{P} \leq 0.01)$ relationship was also observed between the estimated variables (E1 and E2). Correlation coefficients between input (P2 and P4) and estimated variables were statistically significant $(\mathrm{P} \leq 0.01)$ in all breed groups. This parameter was characterised by higher values in paternal groups than in maternal groups. Of all breed groups, the Puławska breed showed the highest values for the correlation coefficient between backfat thickness (P2 and P4) and meat and fat content in the carcass (expressed both in per cent and absolute values). In all breed groups, loin eye height (P4M) was weakly correlated both with the remaining input data and estimated variables (E1 and E2). In maternal and paternal breeds, correlation coefficients between this variable and the estimated values (E1 and E2) were statistically significant $(\mathrm{P} \leq 0.01)$. While the value of correlation coefficient for this relationship was higher in the Puławska breed than in the remaining breed groups, it was not statistically significant. The lack of statistical significance was probably related to the small number of animals in this group.

Table 2. Pearson correlation coefficients between input and estimated data for breed groups: $\mathrm{M}-$ maternal (PLW, PL), P - paternal (Hampshire, Duroc and Pietrain) and Puławska breeds

\begin{tabular}{|c|c|c|c|c|c|}
\hline $\mathrm{P} M$ & $\mathrm{P} 2$ & $\mathrm{P} 4$ & P4M & E1 & E2 \\
\hline P2 & 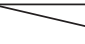 & 0.79 & -0.03 & -0.46 & -0.29 \\
\hline P4 & 0.75 & & -0.10 & -0.43 & -0.32 \\
\hline P4M & -0.27 & -0.35 & & 0.23 & 0.28 \\
\hline E1 & -0.68 & -0.69 & 0.43 & & 0.80 \\
\hline E2 & -0.67 & -0.67 & 0.45 & 0.96 & \\
\hline Pulawska & P2 & P4 & P4M & E1 & E2 \\
\hline $\mathrm{P} 2$ & & 0.92 & -0.26 & -0.85 & -0.76 \\
\hline P4 & & & -0.35 & -0.78 & -0.70 \\
\hline P4M & & & & 0.38 & 0.35 \\
\hline E1 & & & & & 0.94 \\
\hline E2 & & & & & \\
\hline
\end{tabular}

In bold - significant correlation at $\mathrm{P} \leq 0.01$.

In maternal and paternal groups (Table 3), the estimates of parameters of linear models predicting meat content in the carcass (E1 and E2) were statistically significant in the majority of cases. In maternal breeds and the Pulawska breed, supplementation of the classical model with additional data did not significantly improve the estimates. Only in paternal breeds were the parameters of model 4 slightly better than those of the classical model. This model included age on the day of measurement as an additional variable. Attempts to augment the classical models estimating the weight of meat in primal cuts E2 with the use of additional variables improved the parameters of the model only in maternal breeds. The model incorporating body weight, daily gains and age on the day of measurement as additional data showed a standard error $\mathrm{RSE}=1.30$ and multiple correlation coefficient $\mathrm{R}=0.55$. 


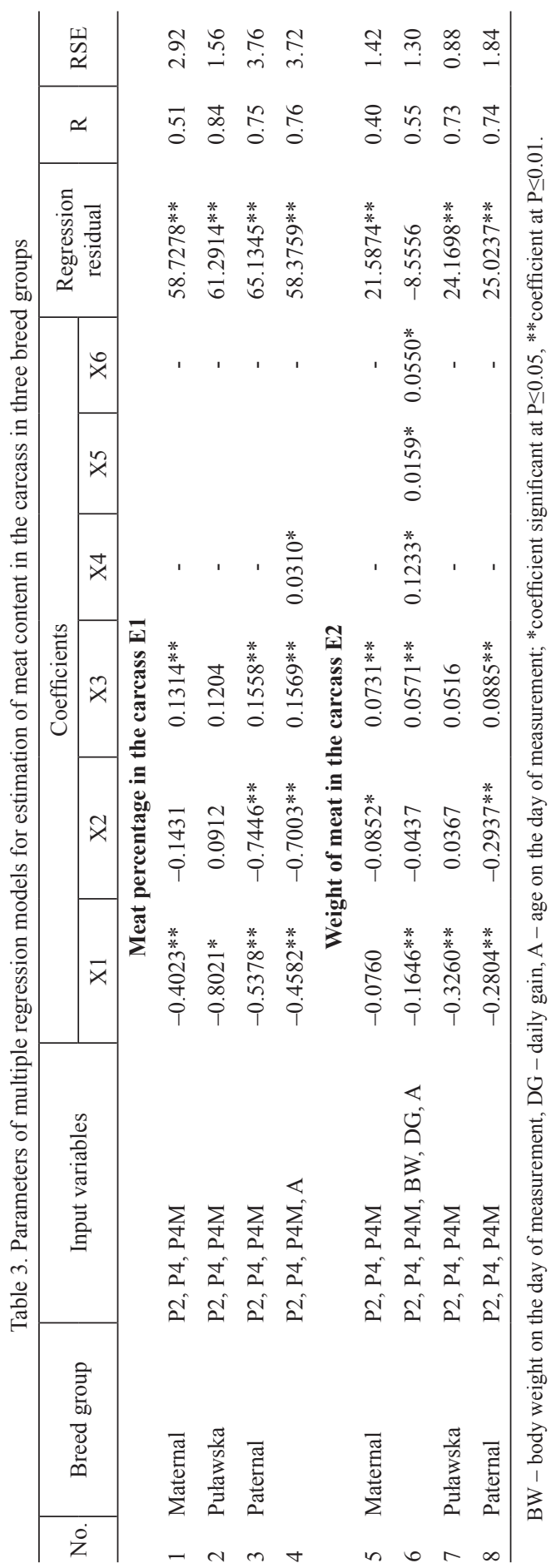




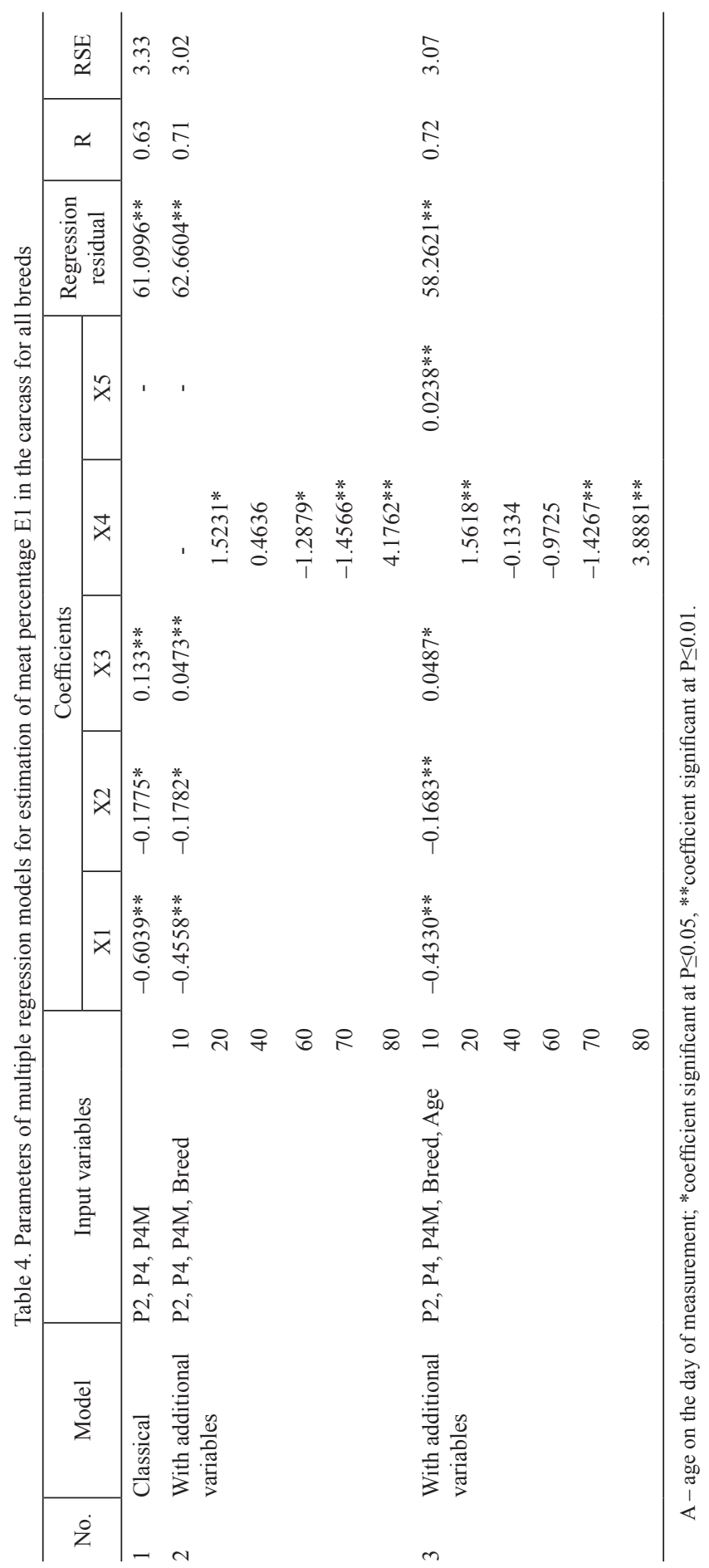




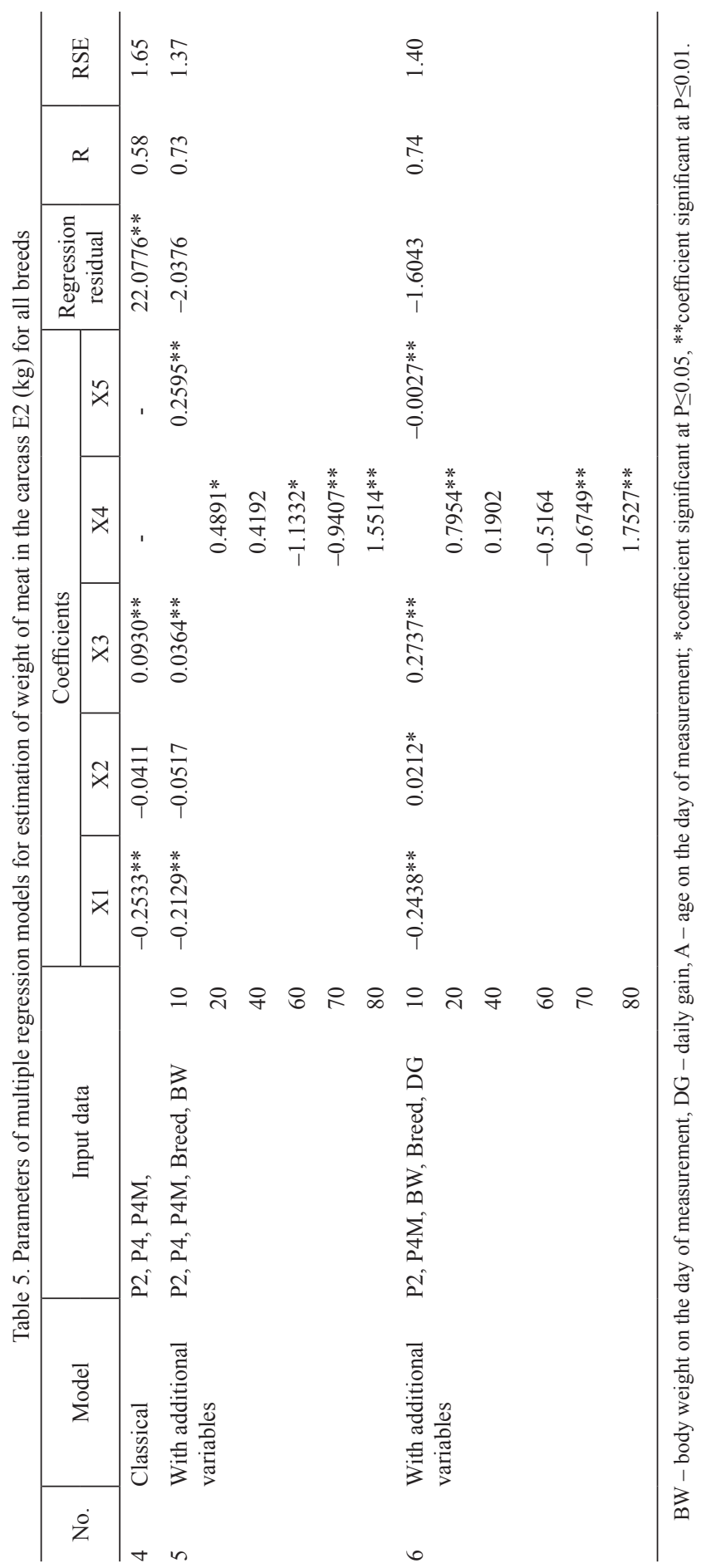


Tables 4 and 5 present the chosen best linear models for estimation of meat content in the carcass and cuts of pigs (E1 and E2, respectively) in all breeds. The equations were chosen based on the values of standard error and multiple correlation coefficient. The presented models estimate meat content based on basic data (P2, P4, P4M, classical model) and on the full set of performance records, including breed. Increasing the number of independent variables in models by breed and age on the day of measurement improved the parameters of estimated meat percentage in the carcass (E1, Table 4), while the addition of breed, body weight and daily gain enabled a more precise estimation of the weight of meat in primal cuts in pigs of all breeds (E2, Table 5). In both classical models and models supplemented with additional variables, the majority of the estimated parameters were statistically significant $(\mathrm{P} \leq 0.01$ or $\mathrm{P} \leq 0.05)$.

\section{Discussion}

The main aim of the present studies was to develop new equations for the estimation of meat percentage in the carcasses of live pigs. Regression coefficients in these equations were calculated based on variables obtained from performance testing of live gilts (ultrasonic measurements of backfat thickness and longissimus dorsi height, body weight and age on the day of measurement, and daily gains) and percentage meat content in the carcass calculated on the basis of detailed dissection conducted at the Pig Testing Station SKURTCh. Apart from equations estimating the meat percentage in the carcass, we also developed equations estimating the weight of meat in pig half-carcasses based on performance records from live animals and the weight of meat in primal cuts $(\mathrm{kg})$ calculated on the basis of detailed dissection. The experimental data were representative of the current pig population reared in this country. The studied gilts of maternal and paternal breeds were characterised by backfat thickness and meatiness similar to the values for each individual breed. The presented differences in the performance records of gilts in different breed groups are in agreement with the results obtained in active populations of these pigs (Eckert et al., 2014).

The present studies indicate highly statistically significant relationships between measurements of backfat thickness and loin muscle height and meat content in the carcass expressed both in per cent and kilograms. Based on the analysis of correlation coefficients, it can be concluded that the changes in backfat thickness significantly alter meat content in the carcass (calculated both as a percentage and as absolute values). This effect is particularly conspicuous in paternal breeds. In all breeds, the changes in loin eye height affected, to a lesser extent, the changes in the estimated values. The obtained correlation coefficients between P2, P4 and P4M measurements and meat percentage in the carcass and weight of meat in cuts are in line with reports from other authors. Studies by Szyndler-Nędza and Różycki (2004) carried out on boars of different breeds demonstrated a statistically significant relationship between backfat thickness (P2, P4) and weight of meat in primal cuts ( $\mathrm{r}=-0.339$ and 
$\mathrm{r}=-0.315$, respectively). The same authors also estimated correlation coefficients between longissimus dorsi height and weight of meat in cuts at a level comparable with the corresponding values in paternal breeds obtained by us. Schinckel et al. (2001), Klimas et al. (2004), Szyndler-Nędza and Eckert (2008), Tyra et al. (2011 a), and Radović et al. (2013) estimated correlation coefficients between backfat thickness measured in live animals and meat percentage in the carcasses of pigs at values ranging from $\mathrm{r}=-0.510$ to $\mathrm{r}=-0.950$. In these studies, correlation coefficients between longissimus dorsi height and carcass meatiness ranged from $\mathrm{r}=0.186$ to $\mathrm{r}=0.523$.

Estimation of meat percentage in carcasses based on a larger number of independent variables increases the accuracy of the estimate. Therefore, in this study, multiple regression coefficients were calculated using, above all, ultrasonic measurements strongly correlated with the meatiness of carcasses. The best linear regression models estimating meat percentage in the carcasses of pigs in breed groups were characterised by variable standard error and multiple correlation coefficients $\mathrm{R}$ (Table 3). In maternal breeds, the classical model was characterised by an error $\mathrm{RSE}=2.92$ and correlation coefficient $\mathrm{R}=0.51$. In paternal breeds, the models were distinguished by high correlation coefficients $(\mathrm{R}=0.75)$ but were affected by standard error exceeding 3\% (RSE=3.76). The classical model developed for all breeds combined (Table 4, model no. 1) was characterised by intermediate parameters in comparison with maternal and paternal breeds $(\mathrm{RSE}=3.33, \mathrm{R}=0.63)$. However, some characteristics of this equation developed on the basis of performance records in live animals and carcass traits of gilts are unsatisfactory. Nevertheless, this result is similar to the parameters obtained earlier for the equation estimating meat percentage in the carcasses of gilts on the basis of analogical performance records (P2, P4, P4M) and carcass traits ( $\mathrm{RSE}=3.18, \mathrm{R}=0.74)$ (Szyndler-Nędza, 2004). Equation parameters superior to those mentioned above were obtained for an equation developed in 2004 based on data from performance testing and SKURTCh data for boars differing in body weight (Szyndler-Nędza and Różycki, 2005). This equation estimated meat percentage in carcasses for the pig population of that time with a lower standard error $\mathrm{SE}=3.01$ and a higher correlation coefficient $\mathrm{R}=0.808$ compared with the models developed for gilts. The parameters of the classical model in our studies were improved by the addition of an independent variable, i.e. breed. This equation had a higher correlation coefficient $\mathrm{R}=0.71$ and a lower standard error $\mathrm{RSE}=3.02$. Improvement of regression equation parameters through the addition of some variables was also documented in reports from other authors. The value of RSD equations in studies on the estimation of meat percentage in the carcasses of pigs based on post-slaughter measurement of carcass traits conducted with the use of different optical devices ranged from $\mathrm{RSD}=2.66$ for an equation with two variables to $\mathrm{RSD}=2.41$ for an equation with four variables. Determination coefficients $\mathrm{R}^{2}$ for these equations amounted to $\mathrm{R}^{2}=0.676$ and $\mathrm{R}^{2}=0.736$, respectively (Schinckel et al., 2010).

In general, it can be stated that multiple regression equations estimating meat percentage in the carcass of live pigs are characterised by a standard error of ca. $3 \%$. Due to the relatively large error of the measuring device (Piglog 105, 2-3\%) and low repeatability of measurements in live animals, the error of such an equation is greater than the analogous error of an equation based on post-slaughter ultrasonic measure- 
ments of the carcass. This conclusion was confirmed by studies by Johnson et al. (2004), who demonstrated that an equation estimating meat percentage in the carcass of pigs developed on the basis of performance testing of live animals using an Aloka 500 apparatus was characterised by a larger standard deviation $(\mathrm{RSD}=3.06)$ than an analogous equation based on carcass measurements $(\mathrm{RSD}=2.93)$. The conclusion was also confirmed by studies by Tyra et al. (2011b) conducted on gilts in Poland with the use of an Aloka 500 apparatus, in which meat percentage in carcasses calculated from performance records in live animals was estimated with an error ranging from $\mathrm{SE}=2.6$ to $\mathrm{SE}=3.5$, while equations estimating meatiness on the basis of measurements of analogical points on carcasses after slaughter showed standard errors from $\mathrm{SE}=2.13$ to $\mathrm{SE}=3.28$. Johnson et al. (2004) also demonstrated that equations based on backfat thickness and longissimus dorsi height overestimated meat percentage in the carcass of fat pigs and underestimated it in meat-type pigs.

The results of the present studies indicate that multiple regression equations utilising variables from performance testing of live animals (P2, P4, P4M) estimate the weight of meat in primal cuts of live animals with an error smaller than that in meat percentage in the carcasses of these pigs. The difference in standard error (RSE) and the superior results of estimates of the weight of meat in cuts was seen both for models calculated in breed groups (Table 3) and in all breeds combined (Tables 4 and 5). Multiple correlation coefficients $\mathrm{R}$ were similar in both types of models. A study by Ayuso et al. (2013) estimating the carcass composition of live Iberian pigs based on ultrasonic measurement with an Aloka 500 apparatus reported a similar standard error in an equation estimating the weight of meat in commercial cuts $(\mathrm{RMSE}=1.53)$ as well as a higher multiple correlation coefficient $(\mathrm{R}=0.73$; $\left.\mathrm{R}^{2}=0.54\right)$. The same authors also revealed that equations estimating meat percentage in cuts were characterised by a lower mean standard error $(\mathrm{RMSE}=1.24)$, but also by a lower determination coefficient $\left(\mathrm{R}^{2}=0.25\right)$, compared with an equation estimating the weight of meat in cuts.

In conclusion, the linear regression equations developed in this study, estimating meat content in carcasses in different breed groups based on three variables (classical model: P2, P4 and P4M), were characterised by variable standard error of the estimate and multiple regression coefficient. The best parameters were obtained for the model estimating meat content in the carcass of pigs of the Puławska breed (E1 [\%] - $\mathrm{RSE}=1.56 ; \mathrm{R}=0.84, \mathrm{E} 2[\mathrm{~kg}]-\mathrm{RSE}=0.88 ; \mathrm{R}=0.73$ ). Analogous regression equations developed for all breeds showed the following values of standard error of the estimate and coefficient R: E1[\%] and $\mathrm{E} 2[\mathrm{~kg}]-\mathrm{RSE}=3.33, \mathrm{R}=0.63$ and $\mathrm{RSE}=1.65$, $\mathrm{R}=0.58$, respectively.

Increasing the number of independent variables did not improve the parameters of equations developed for breed groups. However, when all breeds were combined, the addition of a variable describing the breed to the classical model significantly improved the parameters of the equation estimating $\mathrm{E} 1[\%]$ ( $\mathrm{RSE}=3.02 ; \mathrm{R}=0.71)$. In general, the present studies indicate that equations developed on the basis of performance records in live pigs estimating weight of meat in the carcass were characterised by a lower standard error (RSE) than equations estimating meat percentage in the carcasses of these pigs, including those currently used. 


\section{References}

Ayus o D., González A., Hernández F., Corral J.M., I z qui e rdo M. (2013). Prediction of carcass composition, ham and foreleg weights, and lean meat yields of Iberian pigs using ultrasound measurements in live animals. J. Anim. Sci., 91: 1884-1892.

E c k e r t R., Ż a k G., B e r e t a A. (2014). Results of performance tested gilts (in Polish). Report on pig breeding in Poland. Kraków, Wyd. wł. IZ PIB XXXII, pp. 35-48.

Engel B., La m b o o ij E., B u is t W.G., Ver eijken P. (2012). Lean meat prediction with HGP, CGM, and CSB-Image-Meater, with prediction accuracy evaluated for different proportions of gilts, boars and castrated boars in the pig population. Meat Sci., 90: 338-344.

J o h n s o n R.K., B e rg E.P., G o o d w in R., M a bry J.W., Mi 11 e r R.K., R o b i s o n O.W., S e 11 e rs H., Tok a h M.D. (2004). Evaluation of procedures to predict fat-free lean in swine carcasses. J. Anim. Sci., 82: 2428-2441.

Klimas R., Klimiene A., Rimkevicius S. (2004). Efficiency of breeding pigs selection according to phenotypic evaluation of meatiness. Vet. Zoot. 27: 79-86.

K o u b a M., B on nea u M., N oblet J. (1999). Relative development of subcutaneous, intermuscular and kidney fat in growing pigs with different body compositions. J. Anim. Sci., 77: 622-629.

L is i a k D., B or zut a K. (2014). The influence of the SEUROP grade and weight of pig carcasses on lean meat content evaluated using regression equations from 2003 and 2011 (in Polish). Rocz. Nauk. PTZ, 10: 65-75.

Nis sen P.M., Busk H., Oksama M., S eynaeve M., Gispert M., Walstra P., Hanss on I., Ols en E. (2006). The estimated accuracy of the EU references dissection method for pig carcass classification. Meat Sci., 73: 22-28.

Radović Č., Petrović M., Živković B., Radojković D., Parunović N., Brkić N., D e 1 i ć N. (2013). Heritability, phenotypic and genetic correlations of the growth intensity and meat yield of pigs. Biotech. Anim. Husb., 29: 75-82.

R ó ży c k i M., Ty r a M. (2010). Methodology for evaluating the value of fattening and slaughter pigs carried out in the stations of performance control slaughter pigs (SKURTCh) (in Polish). Report on pig breeding in Poland. Wyd. wł. IZPIB XXVIII, pp. 93-117.

Schinckel A.P., Wagner J.R., Forrest J.C., Einstein M.E. (2001). Evaluation of alternative measures of pork carcass composition. J. Anim. Sci., 79: 1093-1119.

S ch in ckel A.P., Wa g n e r J.R., F orre st J.C, E in s t e in M.E. (2010). Evaluation of the prediction of alternative measures of pork carcass composition by three optical probes. J. Anim. Sci., 88: $767-794$.

S chw a b C.R., B a a s T.J., S t a ld e r K.J., M a b r y J.W. (2007). Deposition rates and accretion patterns of intramuscular fat, loin muscle area, and backfat of Duroc pigs sired by boars from two time periods. J. Anim. Sci., 85: 1540-1546.

S z y nd l er-Nędza M. (2004). Development of regression equations for live estimation of pig carcass lean percentage (in Polish). The doctoral dissertation, Instytut Zootechniki, Kraków, s. 70.

Szyndler-Nędza M., Eckert R. (2008). Relationships between live measurements of backfat and longissimus dorsi thickness and fatness as well as muscularity of carcass, ham and loin of boars and gilts (in Polish). Rocz. Nauk. PTZ., 4: 103-113.

$\mathrm{Szynd}$ ler-Nędza M., Much a A. (2006). Changes in boar backfat and loin muscle thickness as related to body weight and carcass meat percentage. Ann. Anim. Sci., 6: 271-276.

Szyndler-Nędza M., Róży cki M. (2004). Relationships between backfat thickness and loin muscle measurements and carcass muscling in boars. Anim. Sci. Pap. Rep., 22: 561-567.

S z y n d l e r - N ę d z a M., R ó ż y c ki M. (2005). Development of regression equations for live estimation of boar carcass lean percentage (in Polish). Rocz. Nauk. Zoot., 32: 51-60.

Szyndler-Nędza M., Róży cki M., Mucha A., Bereta A., Cie miński Ł, Blichars k i T. (2012). Relationships between performance test traits of pigs (in Polish). Rocz. Nauk. Zoot., 39: 87-96.

Tyra M., Szynd ler-Nędza M., Eckert R. (2011 a). Possibilities of using ultrasonography in breeding work with pigs. Part II - Relations between measurements obtained by different techniques and detailed dissection results. Ann. Anim. Sci., 11: 193-205.

Tyra M., Szynd ler-N ęd za M, Eckert R. (2011 b). Possibilities of using ultrasonography in 
breeding work with pigs. Part III - Estimation of carcass meat content using regression equations developed from ultrasonographic measurement. Ann. Anim. Sci., 11: 357-369.

Z e lenák L., Körmend y L., Va d a - Ková c s M. (2005). The effect of animal types on a simple control method used in the calibration procedure for assessing lean content in pig carcasses. J. Food Engin., 69: 351-358.

Received: 23 VII 2015

Accepted: 31 VIII 2015 